\title{
Forms Of Human-Wildlife Conflict That Exists In Transmara West Sub County, Kenya
}

\author{
${ }^{1}$ Kitampui, Nkiti Jonathan., \& ${ }^{2}$ Rev. Dr. Odhiambo, Elijah Onyango Standslause \\ ${ }^{1}$ Mount Kenya University \\ ${ }^{2}$ Bomet University College, Kenya, Department of Arts, Governance and Communication Studies
}

DOI: 10.29322/IJSRP.11.09.2021.p11713

http://dx.doi.org/10.29322/IJSRP.11.09.2021.p11713

\begin{abstract}
The Wildlife human conflicts, which is seen as a result of the problem of resource utilization in conservation areas has affected the economic development of the Maa community living around the wildlife inhabited areas. It's on this basis that the study sought to investigate on forms of human-wildlife conflict that exists in Transmara West and their effects on economic development of the Maa community. The target population of the study comprised of 450 respondents which was stratified into; members of the Maa community, the wild life wardens, chiefs and sub chiefs and officials of Transmara West Sub County. Data was collected using questionnaires and interviewed guides. The reliability of the collected data was ensured through the test-retest technique while the Pearson methods were used to obtain correlation coefficient of 0.7 . The analyzed data was presented by use of descriptive statistics. Study findings indicated that most people have been victims of human wildlife conflict, crop destruction and injuries caused by wild animals is eminent. Deaths and predation of domesticated animals by dangerous wild animals was supported by $91 \%$ of response rate indicating that it was on a high rise. Therefore, the study recommends that Maa community and its subsidiary clans should be educated about the importance of resource management. Explore and encourage new and innovative mitigation measures based on current and emerging conflict issues and outreach to the Maa community surrounding the wildlife areas to help in diffusing conflict situations.
\end{abstract}

Index Terms- human-wildlife conflict, economic development, protected areas

\section{INTRODUCTION}

$\mathrm{H}$ uman wildlife conflict is currently a worldwide issue, spanning from Asia and Europe where majorly elephants destroy agricultural fields, wild animals prey on domestic animals.

In Africa wild animals roam freely particularly in rangeland areas forcing pastoralist to cope with the damage to and destruction of crops, livestock predation, competition for grazing and water, increased risk of livestock diseases and direct threats to human life. This implies that the human wild life conflict is not restricted to a specific geographical area or climatic conditions but is common to all areas where wildlife and dense human populations have to co-exist and share limited resources (Armah et al, 2014).

Expand in human populations to game parks and reserves threaten wildlife territory in the sense that it contributes to reduction in the availability of natural prey or food sources leads to wild animals seeking alternate sources (Muruthi, 2005). Alternately, new resources created by humans draw wildlife resulting in conflict through their physical interaction due to overlaps in geographical areas (Okello et al, 2014). Further, byproducts of human existence offer un-natural opportunity for wildlife in the form of food and shelter, resulting in amplified obstruction and potentially harsh threat for both man and animals (Woodroffe et al, 2005).

Human-wildlife conflict is extremely common in areas of Kenya where people live near game parks and reservoirs wildlife (Obunde et al. 2005, Western and Waithaka 2005). These reservoirs and game parks are increasingly under threat and opportunities are lost for its gift to the creation of growth, wealth and employment in Kenya. Further, the local communities living near and around the national parks and game reserves are first to pay the price for wildlife through the their interaction by destruction of property, and injuries caused. The case of Maasai Mara and Samburu national parks in Kenya (Irandu , 2003). However, as communities become more sedentary and change their lifestyles and as population increase, there is an inevitable increase in conflict with wildlife over access to resources (Matt $e t$ $a l, 2003)$.

\subsection{Statement of the Problem}

Several studies have been conducted in relation to humanwildlife conflicts in various locations of the world. However, the nature and extent of human wildlife conflict is different from place to place due to their nature of occurrence and effects to the population. This implies that one conflict mitigation strategy applied in one location does not fit in another areas due to sociopolitical, cultural, economic and geographic situations are not the same for all places. Further Human wildlife conflict continues to pose a big challenge to economic development of the communities living near national parks and game reserves.

Kenya's human population has grown the number of conflicts between wildlife and man has multiplies as the animals' habitats have been encroached upon. According to the Daily Nation Newspaper in Kenya, in June 2013, Maasai warriors speared and killed six lions which had entered their community looking for food near Kitengela. Such incidents have become alarmingly common. Thus it is for this reason that the researcher seeks to provide the insight on forms of human-wildlife conflict that exists in Transmara West and their effects on economic development of the Maa community, with aim of establishing long 
term conflict resolution measures and mutual beneficial coexistence between animals and the people leaving a round the Maa triangle, which surrounds the Transmara National Park in Narok County, Kenya.

\subsection{Objective of the Study}

The objective of the study was to examine the form of human-wildlife conflict that exists in Transmara West Sub County, Kenya.

\subsection{Research Question}

What form of human-wildlife conflict exists in Transmara West Sub County?

\subsection{Justification of the Study \\ 1.5.1 Academic Justification}

The study will supplement more literature on areas that has not been previously tackled by the researchers in the same field thus sealing the gaps left. Also, the material can be used as academic sources by those scholars who are pursuing conflict and environmental conservation so that they can understand the causes of conflict between human- wildlife conflicts.

\subsubsection{Policy Justification}

The study suggests significant policy framework through its recommendations of the study. Such recommendations could form policy formulation mechanisms for government policy makers from the wildlife ministry, the Kenya wildlife service, the local community and the county government of Narok.

\section{2.1 MOdels OF HuMAN WILd LIFE CONFLICT}

Human wildlife conflict is a significant and critical threat to conservation worldwide (Nyhus et al., 2005). It occurs when human populations overlap with wildlife requirements resulting in costs to both native residents and animals (Distefano, 2004).

Case studies across several continents imply that HWC is greater in developing nations in which livestock and agricultural land are an integral part of people's lives and income (Distefano, 2004). Therefore, the relative impact of HWC on an individual's economic livelihood is directly correlated to the amount of land owned and the dependence on rural activities (Messmer, 2000).

Fossil documents show that the first hominids fell prey to the animals which they shared habitats and shelters (Berger and Clarke, 1995; Berger, 2006). Crocodiles have attacked and eaten humans and their predecessors in Africa over the last four million years. According to Egyptian historical records (2000 BC), hippopotamuses in the Nile delta fed on human cultivated crops while crocodiles ate domesticated animals and humans.

Human-elephant conflict is as old as agriculture in Africa (Treves and Naughton-Treves, 1999). San or Bushman rock art in Africa frequently portrays people fleeing from predators or other large animals. Pre-colonial and early nineteenth century historians describe areas in Africa and other parts of the world where elephants invaded human cultivations, causing food shortages and leading to the displacement of settlements (Barnes, 1996). Some authors blame colonialism for ruining traditionally harmonious relations between wildlife and local people (Adams and McShane, 1992). In actual fact, from the eighteenth to the mid-twentieth centuries, the larger African mammals were regarded more as a resource to be exploited than a major threat. Ivory formed a cornerstone of the early trade with Europe and the Orient, while meat and hides were essential products both for the African people and colonialists alike. In the twentieth century, with the expansion and development of modern agriculture, exploitation diminished and interaction with large wildlife species came to be increasingly dominated by conflict.

According to Irandu (2003), human wildlife conflict may intensify as the affected population may retaliate against individual animals or entire populations either by illegally killing the offending animal or other animals of the same species, or by illegally taking other wildlife species or other resources under protection, against or lessen cooperation with conservation authorities if they feel that their own needs are being affected by refusing to get involved in conservation programs (Matt,et al, 2003).

The successful recovery of declining or near extinct species populations (fall and Jackson, 2002) through wildlife management and protection from overexploitation (Messmer, 2002) has also led to new conflicts. The social organization, habitat and prey requirements of the species are difficult to accommodate within the human-defined home range, and resulted in many lions straying out of the reserve into local villages (Vijayan and Pati, 2002). In the ranches of North America, European settlement almost exterminated wolves. Recent recovery programmes, however have contributed to the re-colonization by wolves of their original home range, including rural areas; and in the process have increased the potential for conflict, especially where domestic livestock is a major economic activity (Musiani et al., 2003). Strong opposition by international stakeholders to wild population reduction through culling and bans on hunting means that wild animal populations are increasing locally. This, coupled with increased protection, has resulted in a tremendous increase in the wild -life populations as well as changes in animal behaviors.

Due to restrictions in culling, populations of large mammal species such as elephants increase resulting in high densities within the protected areas (Naughton -Treves, 1996), thus leading to incursions outside the park. The combination of elk spending more time on private land, and more private landowners tolerating elk but not elk hunters, has placed a significant portion of the NYEWR - out of administrative control. Wildlife managers have little ability to achieve elk management targets in hunting districts 314 and 317 . Historically these goals were to limit elk population to levels that minimize conflicts with livestock production while providing sustainable hunting opportunities.

The urgency of minimizing conflicts with ranchers has diminished in the Upper Yellowstone Valley with the departure of many of the full-time commercial livestock operations and with it, the functionality of an ecological commons. Hunter access remains a problem because despite growing elk numbers, there are declining opportunities for hunters to access and harvest elk. This paper has provided evidence that ranch sales over the past three decades have encouraged this loss of access, but that the loss of access also occurred on ranch properties in multi-generational 
ownership. The historic relations linking (and later separating) private land owners and public hunters is an area that merits further research.

Human fatalities and injuries are the most serious type of human-wildlife conflict and inspire great fear of and resentment for wildlife despite their relatively rare frequency, which may result in pre-emptive killing (Thirgood et al., 2005). It is estimated that predators and mega-herbivores account for approximately equal amounts of human fatalities per year on a global basis. This is consistent with a seven-year study period in Kenya where 221 people were killed by elephants compared to 250 by predators (Thirgood et al. 2005). Livestock depredation, according to Woodroffe et al. (2005), is the major cause of human-wildlife conflict globally, but has been quantified in only some studies. The preponderance of existing studies focus on individual species and the conservation challenges of these conflicts. For instance, Laikipia district of Kenya has been the site of recent research on livestock depredation by lions (Woodroffe and Frank 2005), African wild dogs (Woodroffe et al., 2005) and leopards (Mizutani, 1999) and a study on livestock depredation primarily focusing on the experiences of privately owned ranches in Laikipia areas (Frank et al., 2006).

Retaliation against predators by local communities in Kenya has been on rise. For instance, 10 lions were killed by Maasai residents of the Kitengela area in 2003, while Nairobi National Park neighbours retaliated on they claim on the loss of about 100 cows and goats to the predators (Gatheru, 2003).

\subsection{Forms of Human-Wildlife Conflict in Transmara West County}

The conflict takes many forms ranging from loss of life or injury to humans, and animals both wild and tamed, to competition over scarce resources to loss and degradation of habitat (Irandu, 2003). Types of human/wildlife conflict that exist in Transmara West Sub County Narok County includes; Human death and injury, Property damage and livestock predation. The study by Irandu, (2003) suffered one major gap relative to this study in that it did not capture the impact of the various forms of human conflict to the economic development of the local people within the habitats of wild animals.

\section{THEORETICAL FRAMEWORK}

Wasike and Odhiambo (2016) discussed the role of theories in guiding the drive of academic studies. They emphasized on the importance of theories in offering compelling and incisive causal explanations with calculated precision under the study. They buttress their argument by quoting Smith (1996) who supported they point of view that theories play the role of predicting, prescribing and evaluating socio-political phenomena therefore making it important hence cannot be ignored.

The conflict theory advanced by Karl Marx (1818-1883) formed the basis of the study. The theory views human society as a collection of competing interests, groups and individuals, each with their own motives and expectations. Implying that all members in society do not have the same values, interests or expectations which are brought according to one's position, privileges, ability, class and wealth. Therefore, agreement tends to appear among those who have similar privileges. This encourages unequal distribution of scarce resources and opportunities therefore resulting into divisions and hostility in the society. Figure 1 Showing Theoretical Framework

\section{Human wildlife conflict Socio-economic dev}

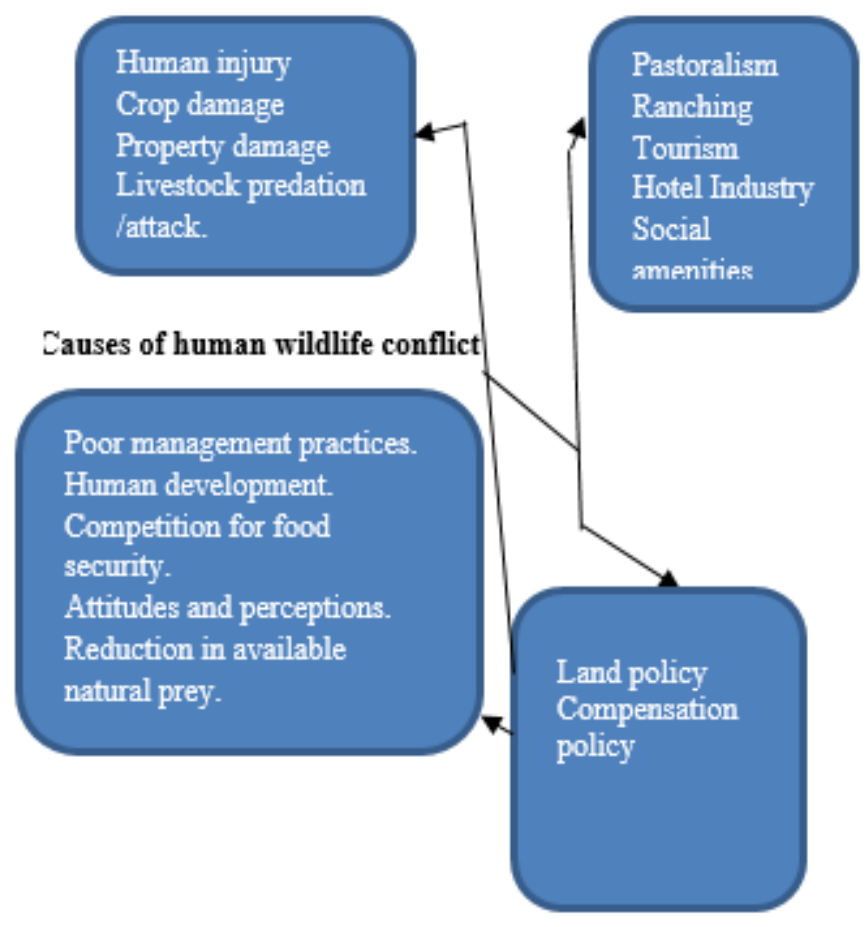

\section{Intervening variable}

Figure 1: Theoretical Model

Source: Researcher, 2020

\section{RESEARCH METHODOLOGY}

\subsection{Research Design}

This study adopted a case study research design. The case study is a way of organizing education or social data and looking at the object to be studied as a whole (Orodho,2005). The main reason for using the case study was that it had the potential to generate rich objective data that could lead to the development of a theory. It was also suitable because the population under study was relatively large and the phenomenon under investigation was observed directly by the researcher.

\subsection{Study location}

The location of the study was Transmara West Sub-County, in Narok County in Kenya. It is worth noting that the decision to choose Transmara West Sub-County, among other sub-county did not minimize the importance of other sub-counties that would have provided similar results. Transmara West Sub- County occupies a total of $2900 \mathrm{~km} 2$. It is located $80 \mathrm{~km}$ to the west of Maasai Mara National Game Reserve.

The Mara River marks its eastern boundary with Narok 
district from which it was separated. To the south it is bordered by the United Republic of Tanzania and Westward by Kuria East Sub- County in Migori County. Kisii and Bomet County are its northern and north-eastern neighbours respectively. The altitude rises from $1524 \mathrm{~m}$ along the Mara River to about $1950 \mathrm{~m}$ above sea level around Kilgoris to $2073 \mathrm{~m}$ above sea level on the hill tops. Topography is gentle to flat in the plains but rather steep on some hills. The catchment population is approximately 274,532 (KNBS, 2009).

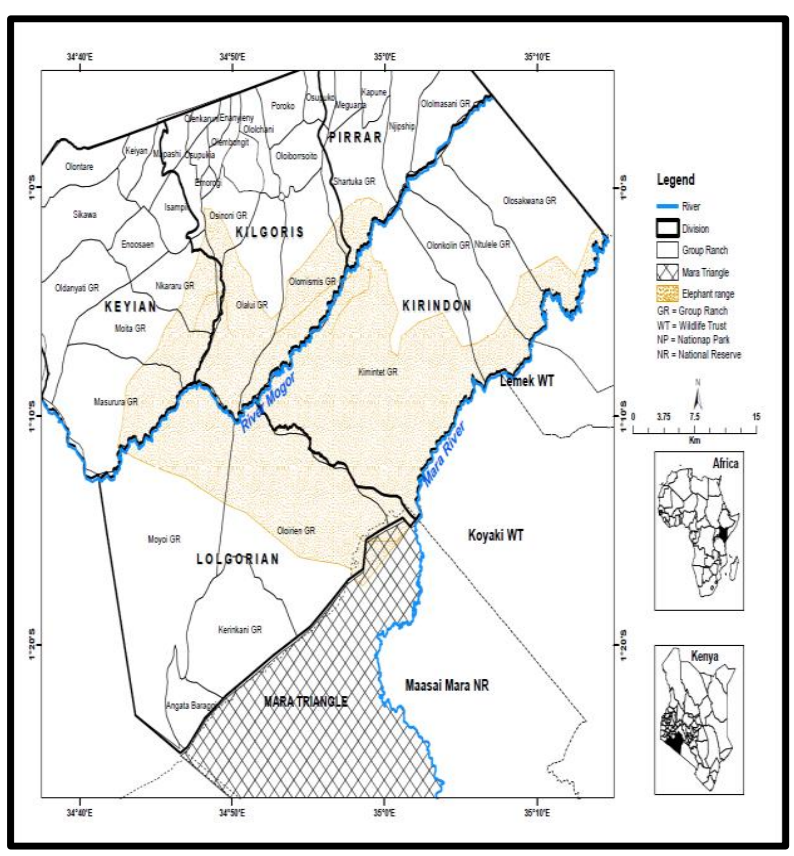

Figure 2: Map of Transmara West Sub County Source: Researcher, 2020

\subsection{Sampling Strategy and the sample size}

The study employed stratified random sampling in selecting the key informants from the non-homogenous population in Transmara West Sub County. According to Mugenda \& Mugenda (2003), 30\% of the target population comprised the sample size. Therefore, the sample size for the study comprised of 80 locals, 5 wardens, 2 chief and 3 assistant chiefs and 50 government officials from Narok Transmara West Sub County which is $30 \%$ of the total target population. Purposive sampling was used to select the respondents for each sub groups from the target population. Therefore the sample size was 140 respondents.

\subsection{Data Collection methods}

Instruments of data collection were; self-administered structured questionnaires, interview schedules and focused group discussions. Questionnaire was appropriate over other methods since it allows for collection of data within a short period of time from a relatively literate population (Oso \& Onen, 2005). Questionnaires were formulated to contain both open and closed ended questions. Interview schedules helped to gather first-hand information from chiefs and wardens.

\section{DATA ANALYSIS AND PRESENTATION}

Collected data was subjected to editing before coding the data and saving in the Ms Excel sheets in order of the research objectives. According to Orodho (2005), editing improves the quality of data for coding. During editing, the researcher checked to ensure that each question had been answered and properly recorded. He further checked for inconsistencies between the answers of different questions and uniformity in interpretation of the questions. Questionnaires that were incomplete and those with irrelevant responses were discarded. Descriptive statistics such as the means, frequencies and percentages was used to analyze the data with the help of a computer package -SPSS version 23. The findings were presented by use of frequencies and percentage in tables.

\section{RESULTS}

\subsection{Forms of Human-Wildlife Conflict}

Researcher asked Wardens, directors of government officials, chiefs and assistant chiefs to indicate forms of humanwildlife conflicts that affect locals. The total number of questionnaires was sixty. Figure 3 is a summary of the findings:

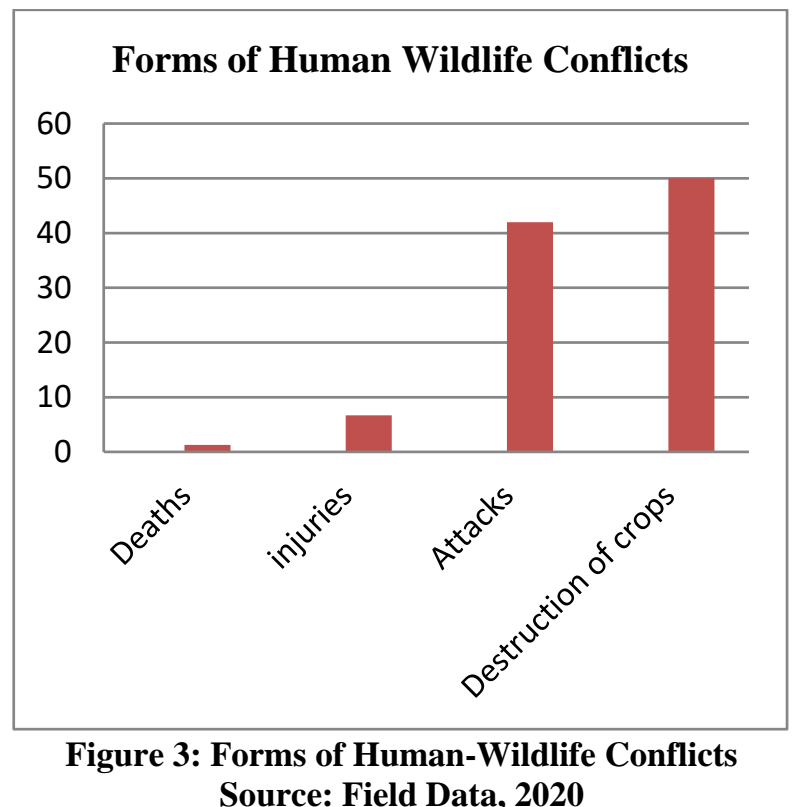

\subsubsection{Human Deaths and Injuries}

Figure 3 indicates that $30(50 \%)$ of the respondents agreed that destruction of crops is the highest form of human-wildlife conflict. 25(42\%) of the respondents agreed that attacks by wildlife on their livestock is the main reason of the conflicts while $1(1.3 \%)$ human deaths and injuries $4(6.7 \%)$ agreed that they contribute to these conflicts.

The most manifested human-wildlife conflict in Transmara west Sub County is destruction of crops. Findings indicate that elephants were considered to be responsible for more deaths than any other large animal in Mara triangle. In an FGD one of the local resident said:

Greatest of the deaths especially those occurring at night are often not registered by the relevant authorities for lack of clear reporting mechanism. Basically large carnivores are responsible 
for various lethal attacks on Humans, while large herbivores, such as elephants, are involved in human deaths every year which occurs when people are protecting their crops against raiding animals usually at night (FGD held on $3^{\text {rd }}$ October, 2018 in Transmara Town).

This assertion indicates that deaths occur as a result of destruction of crops by large mammals is the primary cause of conflicts between humans and wildlife. But this can also be attributed to occupation of humans in dispersal areas in recent times. In an interview, a KWS ranger revealed that leopards and lions have preyed on hundreds of humans in the Mara triangle over the past years. The next sub-section discusses destruction of crops by wildlife. That Lions and hyenas attack mainly cattle during the night while cheetahs attack livestocks.

\subsubsection{Destruction of crops}

Findings further indicates that $30(50 \%)$ of the respondents agreed that destruction of crops is the highest form of humanwildlife conflict across Transmara West Sub County. The occurrence and frequency of crop destruction depends on various factors like availability and type of food sources in the area, the level of human activities in the Maa farms, and the mellowing time of crops as compared to natural food sources.

Various animals forms part of conflict with farming activities in the Transmara West region forming the Mara triangle. For instance, birds, antelopes, buffalos, hippopotamuses, bush pigs and elephants. Elephants do inflict the most damage to the subsistence agriculture in Transmara West Sub County. In an interview a KWS officials argued:

Elephants can destroy a field in a single night raid. The residents try to fence their farms but elephants pull them down and in the process of preventing damage to crops, some are injured (Interview held on $5^{\text {th }}$ October, 2018 in Transmara sub-County).

Also, during dry seasons, elephants breaks into storage bins and feeds on grain thereby contributing to food insecurity, same to baboons and monkeys which also raids food crops. In an FGD, a local farmer lamented:

The Maa community engaging in farming lost crops to elephant raids every year over the previous three years (FGD held on $5^{\text {th }}$ October, 2018 in Transmara sub-County).

This assertion indicates that farming is made difficult in areas where there is direct interaction between the locals and the wildlife. The findings denotes that the KWS is unable to arrest human wildlife conflict situation that is affecting both the locals directly or indirectly and the wildlife.

\subsubsection{Attacks on Domestic Animals}

Findings indicates that $25(42 \%)$ of the respondents agreed that attacks by wildlife on their livestock is the main reason of the existing conflicts. The number and type of domestic animals killed by wildlife varies according to the species, the time of year, and the availability of target (Thirdgood, 2005). Pastoralism being the main source of livelihood for the Maa community, attacks on livestock is poses a challenge especially for a small-scale herder, affecting their livelihood (Thirdgood, 2005).

The higher urgency accorded to wild animals has often inflicted costs on humans. meaning that conservation efforts, including establishment of wildlife zoned areas, have therefore been blamed for causing poverty among the local people through land-living alienation, crop damage, livestock devastation, and diseases spread. Scanty concern over local people's livelihoods, like unfair compensation for damage caused by wild animals to the crops and injury to the locals, affects the level of involvement to support conservation efforts. The affected locals therefore, barely desist from illegal economic activities which are ecologically damaging, as a devised strategy for survival. The illegal activities are geared towards revenge and selfcompensation for damages inflicted by wildlife.

\section{SUMMARY AND CONCLUSION}

The study findings shows that most locals residing near the game parks and reserves have been victims of human wildlife conflict either directly or indirectly. Evidence of crop destruction, injuries, deaths and predation of domesticated animals from dangerous wild animals reveals the challenges that locals face. This was supported by $85 \%$ of the respondents who admitted that human beings have been injured by wild animals, $78 \%, 91 \% 88 \%$ of respondents admitted occurrence of deaths, crop destruction and predation by wild animals respectively. These effects further affects the economy of county and country at large.

\section{RECOMMENDATION}

From the summary and conclusion, the study recommends that Maa community and its subsidiary sets should be educated about the importance of resource management; Explore and encourage new and inventive mitigation measures based on current and evolving conflict issues and outreach to the Maa community to assist in diffusing conflict situations.

\section{REFERENCES}

[1] Adams, W. M., and Hulme, D. (2001a). Conservation and Community: Changing Narratives, Policies and Practices in African Conservation. In African Wildlife and Livelihoods, ed. W. M. Adams and M. Murphree.

[2] Armah, F. A., Boamah, S. A., Quansah, R and Obiri, S. (2014). Management of natural resources in a conflicting environment in Ghana: unmasking a messy policy problem. Journal of Environmental Planning and Management.

[3] Başkaya, Y.S., Gülșen, E and Kara, A. H. (2012). "Relationship between forest protection and hunting tourism in Turkey". African Journal of Agric.

[4] Butler, J. (2000). "The economic costs of wildlife predation on livestock in Gokwe Communal land", Zimbabwe.African Journal of Ecology.

[5] Gay, L.R. (1976)..Educational Research: Competencies for Analysis and Application. Charles Merrill, Columbus, Ohio.

[6] Georgiadis, N. J., F. Ihwagi., Olwero, J. G. N. and Romanach, S. S. (2007a). Savanna herbivore dynamics in a livestock-dominated landscape: I. Dependence on land use, rainfall, density and time. Biological Conservation 137(3):461-472

[7] International Symposium on Society and Resource Management (2004).Human- Wildlife Conflict Session at the International Symposium on Society and resource management

[8] Irandu, E.M. (2003). "Wildlife tourism and local communities in Kenya". Paper Presented atATLAS-Africa Conference, held in Arusha, Tanzania, 20 22 February 2003

[9] Kaczensky, P., Lkhagvasuren, B., Pereladova, O., Hemami, M., Bouskila, A. (2015). Equushemionus. The IUCN Red List of Threatened Species.www.iucnredlist.org

[10] Kathryn, H. (2011). The Expansion of Ecotourism in Tanzania and its Implications for the Maasai, The Ohio State University

[11] Kenya Wildlife Services (2013). Annual report, Nairobi, Kenya 
[12] Kothari, C.R. (2009). Research Methodology: Methods and Techniques. New Delhi: India, New Age Publication.

[13] Lamprey, R. H. and Reid, R. ( 2004). "Expansion of human settlement in Kenya's Maasai Mara: what Future for pastoralism and wildlife?".Journal of Biogeography .

[14] Maasai Mara National Reserve Ecological Management Plan, 2009-2019.

[15] Maasai Mara Science Development Initiative. (2015). Maasai Mara: The Challenges of a World Unique Ecosystem, Phoenix, Nairobi, Kenya

[16] Madden, F.(2004).Creating Coexistence between Humans and Wildlife Global perspectives on Local Efforts to Address Human-Wildlife Conflict

[17] Mugenda, O.M. and Mugenda, A.G. (2003).Research Methods: Quantitative and Qualitative Approaches. Revised 2003. Acts Press, Nairobi.

[18] Muruthi,P. (2005). Human Wildlife Conflict: Lessons Learned From AWF's African Heartlands. African wildlife foundation. Nairobi Kenya

[19] Ogada ,M. J., Nyangena, W and Yesuf ,M. M. (2004). Factors influencing levels of carnivore-livestock Conflicts in Samburu Heartland and proposed mitigation measures. Unpublished consultancy report to African Wildlife

[20] Okello, M.M. and B.E.L. Wishitemi (2006)."Principles for the establishment of community wildlife sanctuaries for ecotourism": Lessons from Maasai Group Ranches, Kenya. African Journal of Business and Economics.

[21] Okello, M.M., Kiringe, J.W. and Warinwa, F. (2014). Prevalence and Severity of Current Human-Elephant Conflicts in Amboseli Ecosystem, Kenya: Insights from the Field and KeyInformants. Natural Resources, 2014.

[22] Orodho, J.A.(2005). Techniques of Writing Research Proposals and Reports in Education and Sciences.1st Edition.Masola Publishers, Nairobi.

[23] Osemeobo, G.J. (1993). "Impact of land use on biodiversity preservation in Nigerian natural ecosystems": A review.Natural Resources Journal, 33, pp. $1015-1025$.

[24] Pander, H.(1995). Land Tenure and Land Policy in the Transmara District, Kenya: Situations and Conflicts.GTZ.

[25] Salvatori V., Corsi F., Milton E. J. and Boitani L. (2001). "The effects of fire and grazing pressure on vegetation cover and small mammal populations in the Maasai Mara National Reserve".African Journal of Ecology 39 (2):2004.
[26] Scott, J. C. (1976). The moral economy of the peasant : rebellion and subsistence in Southeast Asia. New Haven: Yale University Press.

[27] Seno, S. K. and Shaw, W. W. (2002). Land Tenure Policies, Maasai Traditions, and Wildlife Conservation in Kenya.Society \& Natural Resources, 15(1): 79-88.

[28] Terborgh, J., Schaik, C. V ., Davenport, L., Rao, M. (2002). The Problem of People in Parks. In Making parks work: strategies for preserving tropical nature, ed. J.: Island Press.

[29] United Nations Environment Programme (2018). Protected Planet Report Tracking progress towards global targets for protected areas

[30] Wasike, S., \& Odhiambo, E. O. S. (2016). A

[31] Critique of the Usefulness of Theories in Explaining Socio-Political Phenomenon. Asian Journal of Basic and Applied Sciences, 3, 29-33.

[32] Walpole, M., Karanja, G., Sitati, N and Williams, N. L. (2003). Wildlife and People: Conflict and Conservation in Maasai Mara, Kenya:International Institute for Environment and Development, Endsleigh Street, London.

[33] Western, D., Russell, S and Cuthill, I. (2009). The Status of wildlife in Protected Areas Compared to Non-Protected Areas of Kenya.plosone publishers

[34] Woodroffe, R., Lindsey, P. A., Romañach, S. S., Stein, A. and ole Ranah, S M. K. (2005). Livestock Predation by Endangered African Wild Dogs (Lycaon pictus) in Northern Kenya. Biological Conservation, 124:225-234.

\section{AUTHORS}

First Author - Kitampui, Nkiti Jonathan, Mount Kenya University

Second Author - Rev. Dr. Odhiambo, Elijah Onyango Standslause, Bomet University College, Kenya, Department of Arts, Governance and Communication Studies 